\title{
Doctoral E-mentoring: Current Practices and Effective Strategies
}

\author{
David Byrnes \\ Westchester Community College \\ Lida J. Uribe-Flórez, Jesús Trespalacios, and Jodi Chilson \\ Boise State University
}

\begin{abstract}
Effective mentoring has been viewed as the cornerstone of a successful doctoral experience. Traditional doctoral education uses an apprenticeship model for mentoring to help students learn what is required as an academic professional. However, online environments present unique challenges to creating and maintaining mentor-mentee relationships. Using keywords specific to e-mentoring and online graduate education, literature searches were conducted to isolate relevant research from the last decade. From this literature, it was possible to synthesize current practices in e-mentoring and identify effective strategies to use for doctoral students conducting research. Using the Yob and Crawford (2012) framework, results were organized into the following six independent categories: Competence, Availability, Induction, Challenge, Communication, and Emotional Support. Other aspects that impact the mentoring relationship are also discussed.
\end{abstract}

Keywords: E-mentoring, higher education, graduate education, literature review, facultystudent collaboration

Byrnes, D., Uribe-Flórez, L.J., Trespalacios, J., \& Chilson, J. (2019). Doctoral e-mentoring:

Current practices and effective strategies. Online Learning, 23(1), 236-248.

doi:10.24059/olj.v23i1.1446

\section{Doctoral E-mentoring: Current Practices and Effective Strategies}

Mentoring is an important aspect of preparing graduate students to join the academic and practitioner communities. Through mentoring, students may learn to become researchers and create networks that can lead to additional opportunity (Barnes \& Austin, 2009). Mentors can help students improve their knowledge base and research skills while also providing the crucial emotional support students need to persist towards the completion of their dissertation or degree. Additionally, trust is an essential part of a relationship between mentors and mentees in research and dissertation activities, as students rely on supervisors to guide them through their educational journey (Rademaker, O’Connor Duffy, Wetzler, \& Zaikina-Montgomery, 2016; Roumell \& Bolliger, 2017). Effective mentoring has been linked to increasing success rates (Khan \& Gogos, 2013; Pinto Zipp, Cahill, \& Clark, 2009), increasing retention rates (Khan \& Gogos, 2013; Mason, 2012), and helping induct students into the academic community (Curtin, Malley, \& Stewart, 2016; Gardner, 2008), while ineffective mentoring can have the opposite effects (Jones, 2013). 
The act of mentoring can be important to student retention and graduation rates but can also help students become independent researchers in the field. When mentoring students in person, mentors may invite their mentees to collaborate on research or co-present at conferences (Heinrich, 2005; Pinherio, Melkers, \& Youtie, 2014). These activities can significantly improve a student's job prospects after graduation. Ugrin, Odom, and Pearson (2008) found that students are more likely to publish research as graduates if they published with their mentors. Moreover, Heinrich (2005) and Pinherio et al. (2014) found that student-faculty collaboration can ease students' transition into the professional world of academia.

Traditionally, students connect with their mentors face-to-face and easily collaborate with them on research and other academic work (Wikeley \& Muschamp, 2004). However, with the continuous growth of student enrollments in online graduate programs (National Center for Education Statistics [NCES], 2012, 2014), fostering a traditional apprenticeship relationship between faculty and students is difficult. Wikeley and Muschamp (2004) noted that a majority of students in online programs attend part-time and have jobs and families. Since online students often have other responsibilities unrelated to education, mentors may have to invest more effort when assisting students who are transitioning into the academic community (Kumar \& Johnson, 2017b; Wikeley \& Muschamp, 2004).

Argente-Linares, Péres-López, \& Ordóñez-Solana (2017) define e-mentoring "as the process in which electronic media are used as the main channel of communication between the mentor and mentee" (p. 401). Providing online research mentoring presents some communication challenges, including technical difficulties and language barriers, as students may be in places with different communication infrastructure and local languages. Additionally, the mentoring relationship may not be a priority for online students since they are physically remote and probably disconnected from the research community. Regardless of the field of study or degree type, students rely on their mentors for guidance and it is important for mentors to deliver effective support through innovative means. Faculty members may use diverse technological tools to maintain mentee-mentor relationships and adapt strategies used when working with students in person (Doyle, Jacobs, \& Ryan, 2016; Kumar \& Johnson, 2017a; Nasiri \& Mafakheri, 2010).

Despite new perceptions about the quality of online education (Watson, 2016), there are some concerns and differences in how face-to-face and online doctoral education are viewed by employers and scholars. For example, Adams and DeFleur (2005) determined that hiring committee chairpersons prefer potential employees from traditional programs because they perceived these candidates to have better mentoring and socialization experiences. It was also found by Roumell and Bolling (2017) that faculty members of online doctoral programs felt that virtual environments limited the ability to mentor students regarding scholarly activities such as research projects and conference presentations. In addition, the lack of contact with peers and mentors is identified as a cause of attrition for doctoral students (Terrell, Snyder, Dringus, \& Maddrey, 2012). Therefore, it is important for mentors in online doctoral programs to encourage collaboration in research activities among peers and with faculty. This is especially true since online education can provide access to higher degrees for minority groups who have been historically disadvantaged (NCES, 2012, 2015) and who may be at a high risk of dropping out (Gardner, 2008; Sowell, Allum, \& Okahana, 2015).

The main purpose of this paper, by means of a literature review, is to identify current practices and strategies which may help facilitate effective e-mentoring of graduate students conducting research. Based on the Yob and Crawford's (2012) conceptual framework for online mentor-mentee relationships, findings from recent studies may be categorized to understand the 
present state of the mentoring process in online graduate programs. Beyond a synthesis of the literature, research and descriptions of effective initiatives in this area provide a rich picture of student and faculty perceptions of the e-mentoring relationship. Themes become apparent as to what is working and what common pitfalls exist in this process. In the discussion, strategies for effectively mentoring online students to improve success rates will be highlighted as well as recommendations for future study.

\section{Methods}

To conduct this literature review, a combination of the keywords "mentoring" "supervision" or "advising" and "graduate education" or "doctoral education" were searched in the Academic Search Premier database. In an attempt to identify appropriate articles without those terms as keywords, an additional search was conducted that allowed for those keywords to appear in any part of the article. These results were sorted by relevance, and the first 200 articles of each combination were reviewed for potential matches. Parameters were set to only show articles from peer-reviewed journals published since 2008. This date was chosen because Columbaro (2009) published a similar literature review on this topic through 2007. Abstracts of the articles were reviewed for appropriateness. Empirical articles, including case studies, which focused on the distance mentoring relationship between faculty members and graduate students in conducting research, were included. The reference lists of selected articles and non-empirical articles on the topic were also reviewed for additional resources. This process was continued until the reference lists no longer produced any further appropriate articles.

A simultaneous search of the literature was also conducted to ensure that we obtained the most current and relevant research. The key words "mentoring," "graduate," and "online" were used to search an extensive list of databases: Academic Search Premier; Applied Science \& Technology; Education Research Complete; ERIC; Library, Information Science \& Technology; Psychology and Behavioral Sciences Collection; and Teacher Reference Center. This additional search yielded many of the articles we discovered during our initial literature search with one crucial addition - Kumar and Coe (2017) — which, because of relevance and recentness, was added to our collection for review. In total, 19 articles were reviewed.

The articles were read with attention to findings related to the mentoring relationship. These findings were noted and then categorized into themes which were further organized into the six components of the Online Graduate Mentoring Scale in Crawford, Randolph, and Yob (2014) described below. Findings that did not fit into these components were also noted and categorized to be reported in a separated section.

\section{Framework}

Based on literature pertaining to mentoring graduate students and specifically online graduate students, Yob and Crawford (2012) created a conceptual framework for online mentormentee relationships. Crawford et al. (2014) validated this framework by creating a reliable Online Graduate Mentoring Scale.

Through their analyses, they reduced the seven attributes of Yob's and Crawford's (2012) original framework into six independent components: Competence, Availability, Induction, Challenge, Communication, and Emotional Support (see Table 1). The first four represent a broader domain of academic support, while the last two represent the domain of psychosocial support. The six verified attributes were used in this literature review to organize literature and highlight the strategies pertaining to online mentoring of graduate students. Although this 
framework is focused on faculty actions and how they affect students, it would stand to reason that improving faculty action would positively affect student satisfaction, an idea present in many of the studies.

Table 1.

Definition of Online Mentoring Components from Crawford et al. (2014)

\section{Component Defining Characteristics}

Academic Attributes

Competence
Mentor has appropriate education and career background
Mentor has previous experience as a doctoral mentor
Mentor is experienced in research design and methodology
Mentor reviews students work in a timely fashion
Mentor responds to mentees promptly
Mentor allots an appropriate amount of time for communication with
mentees
Mentor collaborates with mentees on research projects and
publications
Induction
Mentor helps mentees network with other professionals
presentation
Mentor assists mentees with connecting their studies with professional
work
Mentor holds mentees to a high academic standard
Mentor helps mentees develop appropriate professional writing skills
Mentor presents new viewpoints for the mentees to consider
Mentor provides targeted feedback on submitted work

Psychosocial Support

Communication Mentor actively listens to mentees' concerns

Mentor clearly states how mentees can improve their work

Mentor holds mentees to firm but realistic deadlines

Mentor is approachable

Emotional Support Mentor addresses mentees emotional needs related to doctoral study

Mentor provide advice on personal problems

Mentor helps mentees build their self-esteem and confidence

Mentor provides positive feedback when work is up to par 


\section{Results and Discussion}

Findings in these articles, when compared to earlier literature, suggest that issues of faculty-student scholarly collaboration in distance education program have endured over time. It was alarming to see that some faculty members are not focused on helping doctoral students enter the academic community through collaborative scholarly experiences (Roumell \& Bolliger, 2017). This could suggest that there has been a lack of improvement in this area since Columbaro's (2009) literature review. As early as 2004, Wikeley and Muschamp called for a new method for faculty working with distance education students. They argued that institutions should strive to provide an experience for students in online programs equal to those in traditional degree programs. They charge faculty members with becoming experts in a student's research topic, which is still a concern (Kumar \& Johnson, 2017a). Moreover, Wikeley and Muschamp (2004) encouraged faculty to help induct students into the academic world, which may still be lacking since collaborative research was found to be relatively low (Erichsen, Bolliger, \& Halupa, 2014). This type of research has the potential to make students aware of new research methods and help them understand the research process (Melrose, 2006). It has been found that students felt their remote setting limited their ability to learn new research methods from faculty members (Andrew, 2012).

This literature review shows that the concerns of faculty members and students have not changed. Many studies (Kumar \& Coe, 2017; Rademaker et al., 2016; Terry \& Ghosh, 2015) have highlighted the importance of honest and substantive feedback for the improved scholarship recommended by Wikeley and Muschamp (2004). Those authors also recommend a cohort model which seems to be frequently utilized (Crossouard, 2008; Ewing, Mathieson, Alexander, \& Leafman, 2012; Kumar \& Coe, 2017; Kumar \& Johnson, 2017a). Additionally, Melrose (2006) argued that research collaborations between faculty members and students should be in the student's best interest since online graduate students are more likely to have other commitments. Therefore, their time is valuable and should not be exploited. This may explain why some faculty members encourage students to conduct research but do not necessarily feel the need to participate themselves (Andrew, 2012; Grady, 2016; Jacobs, Doyle, \& Ryan, 2015; Rademaker et al., 2016; Roumell \& Bolliger, 2017). Melrose (2006) also mentioned the importance of trust, effective communication, reasonable goal setting, and accountability for deadlines. All of these factors remain important to a successful online mentoring relationship (Doyle et al., 2016; Erichsen et al., 2014; Kumar \& Coe, 2017; Rademaker et al., 2016; Roumell \& Bolliger, 2017; Stadtlander \& Giles, 2010).

\section{Strategies}

It has been found that multiple strategies can be utilized by faculty who are online doctoral mentors to support students' research experiences. Table 2 includes the strategies we have identified in the literature and the sources that refer to them, followed by a more detailed discussion about how mentors can utilize these strategies. 
Table 2.

Summary of Strategies for Successful E-mentoring

\begin{tabular}{|c|c|c|}
\hline Component & Strategy & Sources \\
\hline \multirow[t]{4}{*}{ Competence } & Draw on personal experience & Erichsen et al. (2014) \\
\hline & $\begin{array}{l}\text { Provide resources for students to } \\
\text { read }\end{array}$ & $\begin{array}{l}\text { Andrew (2012); Kumar \& Coe (2017); } \\
\text { Kumar \& Johnson (2017a); Kumar et al. } \\
(2013)\end{array}$ \\
\hline & $\begin{array}{l}\text { Help students select a } \\
\text { dissertation topic }\end{array}$ & Terry \& Ghosh (2015); Welch (2017) \\
\hline & Seek professional development & $\begin{array}{l}\text { Kumar \& Johnson (2017a); Roumell \& } \\
\text { Bolliger (2017) }\end{array}$ \\
\hline \multirow[t]{3}{*}{ Availability } & $\begin{array}{l}\text { Be flexible on ways to } \\
\text { communicate (technology, } \\
\text { times) }\end{array}$ & $\begin{array}{l}\text { Andrew (2012); Crossouard (2008); de Beer } \\
\text { \& Mason (2009); Doyle et al. (2016); } \\
\text { Erichsen et al. (2014); Kumar \& Coe (2017); } \\
\text { Kumar \& Johnson (2017a); Kumar et al. } \\
\text { (2013); Loureiro et al. (2010); Roumell \& } \\
\text { Bolliger (2017); Stadtlander \& Giles (2010) }\end{array}$ \\
\hline & Let students set the pace & $\begin{array}{l}\text { Doyle et al. (2016); Kumar \& Johnson } \\
\text { (2017a); Roumell \& Bolliger (2017) }\end{array}$ \\
\hline & Meet increasingly frequently & Andrew (2012) \\
\hline \multirow[t]{4}{*}{ Induction } & $\begin{array}{l}\text { Demonstrate the research } \\
\text { process through collaboration }\end{array}$ & $\begin{array}{l}\text { Ewing et al. (2012); Roumell \& Bolliger } \\
\text { (2017); Stadtlander \& Giles (2010) }\end{array}$ \\
\hline & $\begin{array}{l}\text { Encourage students to present } \\
\text { and publish }\end{array}$ & $\begin{array}{l}\text { Andrew (2012); Grady (2016); Jacobs et al. } \\
\text { (2015); Rademaker et al. (2016); Roumell \& } \\
\text { Bolliger (2017) }\end{array}$ \\
\hline & Encouraging independence & $\begin{array}{l}\text { Rademaker et al. (2016); Roumell \& Bolliger } \\
\text { (2017) }\end{array}$ \\
\hline & Discuss career goal & $\begin{array}{l}\text { Doyle et al. (2016); Kumar \& Johnson } \\
\text { (2017a) }\end{array}$ \\
\hline \multirow[t]{2}{*}{ Challenge } & $\begin{array}{l}\text { Provide honest and substantive } \\
\text { feedback }\end{array}$ & $\begin{array}{l}\text { Andrews (2016); Kumar \& Coe (2017); } \\
\text { Rademaker et al. (2016); Terry \& Ghosh } \\
(2015)\end{array}$ \\
\hline & $\begin{array}{l}\text { Support the development of } \\
\text { writing skills }\end{array}$ & $\begin{array}{l}\text { Andrew (2012); Crossouard (2008); Jacobs } \\
\text { et al. (2015); Kumar \& Johnson (2017a); } \\
\text { Welch (2017) }\end{array}$ \\
\hline \multirow[t]{2}{*}{ Communication } & $\begin{array}{l}\text { Set reasonable goals and keep } \\
\text { students accountable }\end{array}$ & $\begin{array}{l}\text { Doyle et al. (2016); Erichsen et al. (2014); } \\
\text { Kumar \& Coe (2017); Stadtlander \& Giles } \\
\text { (2010) }\end{array}$ \\
\hline & $\begin{array}{l}\text { Maintain open and supportive } \\
\text { communication }\end{array}$ & $\begin{array}{l}\text { Erichsen et al. (2014); Rademaker et al. } \\
\text { (2016); Stadtlander \& Giles (2010); Terry \& } \\
\text { Ghosh (2015) }\end{array}$ \\
\hline \multirow[t]{2}{*}{$\begin{array}{l}\text { Emotional } \\
\text { Needs }\end{array}$} & Provide encouragement & $\begin{array}{l}\text { Doyle et al. (2016); Erichsen et al. (2014); } \\
\text { Kumar \& Johnson (2017a); Rademaker et al. } \\
\text { (2016); Terry \& Ghosh (2015) }\end{array}$ \\
\hline & $\begin{array}{l}\text { Present strategies to reduce } \\
\text { feelings of isolation }\end{array}$ & $\begin{array}{l}\text { Andrew (2012); Crossouard (2008); Kumar } \\
\text { \& Coe (2017); Kumar \& Johnson (2017a); } \\
\text { Loureiro et al. (2010); Rademaker et al. } \\
\text { (2016); Welch (2017) }\end{array}$ \\
\hline
\end{tabular}




\section{Competence}

Conducting research is usually a new experience for doctoral students and having a mentor who is a competent researcher can help guide students through the dissertation process. One strategy mentors, especially mentors with limited experience, can use to help their mentees is by drawing on their own doctoral and research experiences (Erichsen et al., 2014). By imparting knowledge as to what does and does not work well in a research environment, mentors can help save students from unnecessary stress and avoidable challenges. Another way mentors may help students avoid pitfalls is through providing a reading list (Andrew, 2012; Kumar \& Coe, 2017; Kumar \& Johnson, 2017a; Kumar, Johnson, \& Hardemon, 2013). This keeps students abreast of the current literature in their field and also highlights potential research methods and topics. Students may feel lost or indecisive about a research topic when presented with a variety of potential areas of research. Unlike traditional doctoral programs, students in online programs are less likely to work directly with professors on research projects which may lead to a dissertation project. To support these students, mentors of online doctoral students may provide dissertation topic suggestions to their mentees to keep them on track (Terry \& Ghosh. 2015; Welch, 2017). Finally, since online mentors have reported feeling underprepared to provide doctoral students with proper support, professional development should be sought (Kumar \& Johnson, 2017a; Roumell \& Bolliger, 2017). Through professional development, mentors build skills which, in turn, benefit students.

\section{Availability}

Being accessible to remote students is one of the most important ways that mentors can support their mentees. Since online students are more likely to have other commitments, it is uniquely important to build a good mentoring relationship (Wikeley \& Muschamp, 2004). In order to be a solid presence in mentees' lives, mentors should establish regular and frequent meetings to stay involved (Andrew, 2012). Through these meetings, mentors can discuss other ways to be available, including flexibility and pace. Student crave mentors who are open to several forms of communication and meeting times which may suit their individual needs (Andrew, 2012; Crossouard. 2008; Doyle et al., 2016; Erichsen et al., 2014; Kumar \& Coe, 2017; Kumar \& Johnson, 2017a; Kumar et al., 2013; Roumell \& Bolliger, 2017; Stadtlander \& Giles, 2010). Mentors may consider innovative communication tools which allow for asynchronous communication for those in different time zones, such as discussion boards and learning management systems (de Beer \& Mason, 2009; Loureiro, Huet, Baptista, \& Casanova, 2010). An open conversation at the beginning of the mentoring relationship allows both parties to determine which forms of communication and what times are best. Additionally, this will allow both mentors and mentees to ensure that they have the technical capabilities to meet in the agreed upon modes of communication. Finally, they can also discuss pace; again, since online doctoral students have various responsibilities outside of school it is important to establish a reasonable timeline that fits each student's needs (Doyle et al., 2016; Kumar \& Johnson, 2017a; Roumell \& Bolliger, 2017).

\section{Induction}

In online and blended doctoral programs, faculty-student research collaborations may be lacking (Erichsen et al., 2014) despite the fact that this is one of the most beneficial experiences doctoral students can have. Through collaborative research, students learn firsthand what goes into successful research and the details of the publication process (Ewing et al., 2012; Roumell \& Bolliger, 2017; Stadtlander \& Giles, 2010). This sort of experiential learning helps students gain an understanding of what will be expected in the dissertation process. This practice may be impractical for certain mentoring relationships, and mentors may turn to other methods which 
engender induction. Mentors can encourage students to be independent and take on research related projects of their own (Rademaker et al., 2016; Roumell \& Bolliger, 2017). Students can get a sense of how to conduct research for their dissertation by conducting a smaller research project on their own or with colleagues. Mentors can provide support to students by encouraging them to consider publishing their work or presenting it at regional or national conferences which can introduce them to the research community (Andrew, 2012; Grady, 2016; Jacobs et al., 2015; Rademaker et al., 2016; Roumell \& Bolliger, 2017). Mentors may suggest specific conferences or academic journals best suited for the student's work. However, not all students pursuing a doctorate intend to enter academia. Mentors should discuss students' career goals to determine which activities will help them most in the future (Doyle et al., 2016; Kumar \& Johnson, 2017a).

\section{Challenge}

Research and dissertation processes require openness to criticism and a willingness to improve. Mentors can help mentees become more comfortable with this process by providing honest and substantive feedback (Andrews, 2016; Kumar \& Coe, 2017; Rademaker et al., 2016; Terry \& Ghosh, 2015). There may be some disagreement between faculty and student preferences when it comes to feedback. Students crave more direct edits, while faculty members prefer to provide more holistic critiques. One strategy to remedy this is peer feedback, in which students provide specific corrections while professors address overarching areas of concern (Crossouard, 2008; Loureiro et al. 2010). Peer feedback also familiarizes students with the process of submitting work to refereed journals where their work will be reviewed by peers. With feedback, students develop and improve their skills, particularly in academic writing, which is a unique skill that can be improved through practice (Andrew, 2012; Crossouard, 2008; Jacobs et al., 2015; Kumar \& Johnson, 2017a; Welch, 2017). Professors and mentors should help support the development of academic writing skills throughout the doctoral program so that students are seasoned writers when they begin their dissertations.

\section{Communication}

Beyond when and how to communicate, it is important to establish quality communication in a mentoring relationship. Mentors should strive to provide open and supportive communication to their mentees (Erichsen et al., 2014; Rademaker et al., 2016; Stadtlander \& Giles, 2010; Terry \& Ghosh, 2015), and maintain an approachable attitude so that students feel comfortable discussing challenges or sensitive issues. To encourage this type of open relationships, mentors may actively encourage students to ask questions early in the relationship. While supportive communication is crucial to a strong mentoring relationship, it is also necessary to help students stay on track. It is important to allow students to set the pace, but students must be held accountable for achieving goals (Doyle et al., 2016; Erichsen et al., 2014; Kumar \& Coe, 2017; Stadtlander \& Giles, 2010). This type of accountability will help students perfect their time management skills which will ultimately help them complete their dissertation.

\section{Emotional Needs}

Completing a graduate degree, especially a doctoral degree, can be a stressful experience, and students may need emotional support from their mentors. Again, since online students are physically removed from their academic community, it is important for mentors to provide encouragement so that students feel more confident and persist (Doyle et al., 2016; Erichsen et al., 2014; Kumar \& Johnson, 2017a; Rademaker et al., 2016; Terry \& Ghosh, 2015). To help build confidence, mentors can allow students to take the lead in mentoring meetings. Mentors can also help struggling students by listening to what challenges they face and providing potential solutions to the problem. Distance education students commonly experience feelings of isolation which 
mentors may be able to help address (Andrew, 2012; Crossouard, 2008; Kumar \& Coe, 2017; Kumar \& Johnson, 2017a; Loureiro et al., 2010; Rademaker et al., 2016; Welch, 2017). Mentors alleviate feelings of isolation by creating a sense of community among students, providing support, providing clear guidelines for students' work, and encouraging students to seek out support from those around them. Addressing students' emotional needs may come easily to mentors in certain fields such as education or counseling, but others may struggle with providing this kind of support. Much like competence, mentors may seek professional development to improve their skills in this area.

\section{The Effects of Distance}

Some factors that affect the mentoring process are unique to the setting itself and are not easily categorized into mentor behavior attributes. Mentors should be mindful of these limitations and adopt strategies to counteract these effects. Kumar and Johnson (2017a) found the loss of nonverbal cues normally associated with in-person communication methods to be a concern for faculty members. This finding may be related to the fact that students prefer synchronous communication methods (Kumar et al., 2013). Through synchronous communication, nonverbal cues such as tone of voice, and facial and body language may be restored. However, White and Coetzee (2014) found that supervision can be effective even through email, which is arguably the communication tool least similar to face-to-face contact.

One way to increase student satisfaction suggested by Kumar and Coe (2017) and Grady (2016) is the establishment of a residency requirement for students, even if voluntary. This might confirm a finding by Erichsen et al. (2014) that students in blended programs were more satisfied with mentoring than those in online-only programs. Since an in-person component may facilitate synchronous communication, those two ideas may validate each other. Finally, Loureiro et al. (2010) and Andrew (2012) both noted that students appreciate some degree of face-to-face interactions with their mentors. Additionally, Erichsen et al. (2014) discovered that the lack of mentoring or professional development opportunities for students as a result of being in a distance education program can lead to student dissatisfaction. For this reason, mentors may consider incorporating professional development into any residency requirement of an online doctoral program.

\section{Making Use of the Online Graduate Mentoring Scale}

Online graduate students represent a diverse group of people whose needs may vary. As such, Crawford et al.'s (2014) Online Graduate Mentoring Scale may be an effective tool to pair students with potential faculty members based on individual needs. Students hoping to pursue a career in academia may benefit from a mentor who strongly encourages collaboration and other aspects of the induction component. On the other hand, faculty members with strong emotional support and availability characteristics may be well suited for students who juggle many responsibilities and need encouragement to persist. Finally, mentors who are strong in the competence and challenge components may be especially important for students from disadvantaged backgrounds who need additional academic support. Program leaders may consider administering this scale to faculty members and an adapted version to students to help find appropriate matches. This is just one way faculty members and universities may use the Online Graduate Mentoring Scale to better serve online graduate students to help ensure success and improve completion rates. 


\section{Conclusion}

\section{Limitations and Recommendations for Future Study}

The goal of this paper was to provide strategies to professors working with online students conducting research activities and therefore has some inherent limitations. Since this was not an empirical study or a meta-analysis of previous studies, additional research may be conducted to identify new or emerging e-mentoring strategies. As this review provided a comprehensive overview research in this area, gaps in the literature become apparent. Most of the researchers approached this topic from the student perspective, omitting important information about faculty opinions. This paper focused on how student and faculty opinions may inform faculty members' actions. However, research into the current actions of faculty will help to improve an understanding of this unique relationship with distance students. Moreover, since the majority of the articles were qualitative in nature, future quantitative or mixed methods studies could help contextualize some of the findings and highlight specific areas which may be improved.

The scope of this literature review may also be seen as a limitation. Search terms were chosen to optimize the breadth of results and examining reference lists helped to identify additional articles. However, other useful research may have been inadvertently missed. Additionally, the parameters that research be published in the past decade may have excluded older yet still relevant research. While Columbaro (2009) reviewed several studies in this area, that review was not as exhaustive as the present one. Furthermore, since the focus was on doctoral programs with research requirements, the strategies may not be applicable to all terminal degree programs. For instance, professional doctorates such as M.D and J.D. generally do not require a research component, and mentors in these programs may utilize decidedly different strategies when supporting students. 


\section{References}

Adams, J., \& DeFleur, M. (2005). The acceptability of a doctoral degree earned online as a credential for obtaining a faculty position. The American Journal of Distance Education, 19(2), 71-85.

Andrew, M. (2012). Supervising doctorates at a distance: Three trans-Tasman stories. Quality Assurance in Education, 20(1), 42-53.

Andrews, K. (2016). Correlation between mentors and learners perceptions of mentors behaviors in completing online doctoral dissertations. Journal of Higher Education Theory and Practice, 16(2), 71-80.

Argente-Linares, E., Péres-López, M. C., \& Ordóñez-Solana, C. (2017). Practical experience of blended mentoring in higher education. Mentoring \& Tutoring: Partnership in Learning, 24(5), 399-414.

Barnes, B. J., \& Austin, A. E. (2009). The role of doctoral advisors: A look at advising from the advisor's perspective. Innovative High Education, 33, 297-315.

Columbaro, N. (2009). e-Mentoring possibilities for online doctoral students: A literature review. Adult Learning, 20(3-4), 9-15.

Crawford, L. M., Randolph, J. J., \& Yob, I. M. (2014). Theoretical development, factorial validity, and reliability of the online graduate mentoring scale. Mentoring \& Tutoring: Partnership in Learning, 22(1), 20-37.

Crossouard, B. (2008). Developing alternative models of doctoral supervision with online formative assessment. Studies in Continuing Education, 30(1), 51-67.

Curtin, N., Malley, J., \& Stewart, A. J. (2016). Mentoring the next generation of faculty: Supporting academic career aspirations among doctoral students. Research in Higher Education, 57, 714-738.

de Beer, M., \& Mason, R. B. (2009). Using a blended approach to facilitate postgraduate supervision. Innovations in Education and Teaching International, 46(2), 213-226.

Doyle, N., Jacobs, K., \& Ryan, C. (2016). Faculty mentors' perspectives on e-mentoring postprofessional occupational therapy doctoral students. Occupational Therapy International, 23(4), 305-317.

Erichsen, E. A., Bolliger, D. U., \& Halupa, C. (2014). Students satisfaction with graduate supervision in doctoral programs delivered in distance education settings. Studies in Higher Education, 39(2), 321-338.

Ewing, H., Mathieson, K., Alexander, J. L., \& Leafman, J. (2012). Enhancing the acquisition of research skills in online doctoral programs: The Ewing modelC. Journal of Online Learning and Teaching, 8(1), 34-44.

Gardner, S. K. (2008). Fitting the mold of graduate school: A qualitative study of socialization in doctoral education. Innovative Higher Education, 33, 125-138.

Grady, M. L. (2016). Doctoral students in a distance program: Advising and degree completion strategies. Journal of Academic Administration in Higher Education, 12(2), 49-52. 
Heinrich, K. T. (2005). Halfway between receiving and giving: A relational analysis of doctorate-prepared nurse--scholars' first 5 years after graduation. Journal of Professional Nursing, 21(5), 303-313.

Jacobs, K., Doyle, N., \& Ryan, C. (2015). The nature, perception, and impact of e-mentoring on post-professional occupational therapy doctoral students. Occupational Therapy in Health Care, 29(2), 201-213.

Jones, M. (2013). Issues in doctoral studies - forty years of journal discussion: Where have we been and where are we going? International Journal of Doctoral Studies, 8, 83-104.

Khan, R., \& Gogos, A. (2013). Online mentoring for biotechnology graduate students: An industry-academia partnership. Journal of Asynchronous Learning Networks, 17(1), 89107.

Kumar, S., \& Coe, C. (2017). Mentoring and student support in online doctoral programs. American Journal of Distance Education, 31(2), 128-142.

Kumar, S., \& Johnson, M. (2017a). Mentoring doctoral students online: Mentor strategies and challenges. Mentoring \& Tutoring: Partnership in Learning, 25(2), 202-222.

Kumar, S., \& Johnson, M. (2017b). Online mentoring of dissertations: The role of structure and support. Studies in Higher Education. Retrieved from https://www.tandfonline.com/doi/full/10.1080/03075079.2017.1337736

Kumar, S., Johnson, M., \& Hardemon, T. (2013). Dissertations at a distance: Students' perceptions of online mentoring in a doctoral program. International Journal of Elearning \& Distance Education, 27(1). Retrieved from http://www.ijede.ca/index.php/jde/article/view/835/1481

Loureiro, M., Huet, I., Baptista, A., \& Casanova, D. (2010). Using ICT to enhance the online research supervision process. Acta Academica, 1, 151-174.

Mason, M. M. (2012). Motivation, satisfaction, and innate psychological needs. International Journal of Doctoral Studies, 7, 259-277.

Melrose, S. (2006). Mentoring online graduate students: Partners in scholarship. Education for Primary Care, 17(1), 57-62.

Nasiri, F., \& Mafakheri, F. (2010). Postgraduate research supervision at a distance: A review of challenges and strategies. Studies in Higher Education, 40(10), 1962-1969.

National Center for Education Statistics. (2012). Number and percentage of graduate students taking distance education or online classes and degree programs, by selected characteristics: Selected years, 2003-04 through 2011-12. Retrieved from https://nces.ed.gov/programs/digest/d15/tables/dt15 311.32.asp

National Center for Education Statistics. (2014). Distance learning. Retrieved from https://nces.ed.gov/fastfacts/display.asp?id=80

National Center for Education Statistics. (2015). Selected statistics for degree-granting postsecondary institutions that primarily offer online programs, by control of institution and selected characteristics: 2015 . Retrieved from https://nces.ed.gov/programs/digest/d16/tables/dt16_311.33.asp 
Pinherio, D., Melkers, J., \& Youtie, J. (2014). Learning to play the game: Student publishing as an indicator of future scholarly success. Technological Forecasting \& Social Change, 81, 56-66.

Pinto Zipp, G., Cahill, T., \& Clark, M. (2009). The role of collaborative scholarship in the mentorship of doctoral students. Journal of College Teaching \& Learning, 6(8), 29-36.

Rademaker, L. L., O’Connor Duffy, J., Wetzler, E., \& Zaikina-Montgomery, H. (2016). Chair perceptions of trust between mentor and mentee in online doctoral dissertation mentoring. Online Learning, 20(1), 1-13.

Roumell, E. A. L., \& Bolliger, D. U. (2017). Experience of faculty with doctoral student supervision in programs delivered via distance. The Journal of Continuing Higher Education, 65(2), 82-93.

Sowell, R., Allum, J., \& Okahana, H. (2015). Doctoral initiative on minority attrition and completion. Washington, DC: Council of Graduate Schools.

Stadtlander, L. M., \& Giles, M. J. (2010). Virtual instruction: A qualitative research laboratory course. Teaching of Psychology, 37(4), 281-286.

Terrell, S., Snyder, M., Dringus, L., \& Maddrey, E. (2012). A grounded theory of connectivity and persistence in a limited residency doctoral program. The Qualitative Report, 17(62), 1-14. Retrieved from http://www.nova.edu/ssss/QR/QR17/terrell.pdf

Terry, T., \& Ghosh, R. (2015). Mentoring from different social spheres: How can multiple mentors help in doctoral student success in Ed.D. programs? Mentoring \& Tutoring: Partnership in Learning, 23(3), 187-212.

Ugrin, J. C., Odom, M. D., \& Pearson, J. M. (2008). Exploring the importance of mentoring for new scholars: A social exchange perspective. Journal of Information Systems Education 19(3), 343-350.

Watson, C. (2016). Acceptance of online education degrees by human resource recruiters (Order No. 10248132). Available from ProQuest Central; ProQuest Dissertations \& Theses Global. (1868431579). Retrieved from https://search.proquest.com/openview/5ab166779b480bfc8433a2d6aca877d4/1?pqorigsite $=$ gscholar $\& \mathrm{cbl}=18750 \&$ diss $=\mathrm{y}$

Welch, S. (2017). Virtual mentoring program within an online doctoral nursing education program: A phenomenological study. International Journal of Nursing Education Scholarship, 14(1), doi:10.1515/ijnes-2016-0049

White, T., \& Coetzee, E. (2014). Postgraduate supervision: E-mail as an alternative. African Education Review, 11(4), 658-673.

Wikeley, F., \& Muschamp, Y. (2004). Pedagogical implications of working with doctoral students at a distance. Distance Education, 25(1), 125-142.

Yob, I., \& Crawford, L. (2012). Conceptual framework for mentoring doctoral students. Higher Learning Research Communications, 2(2), 34-47. 